University of Nebraska - Lincoln

DigitalCommons@University of Nebraska - Lincoln

$5-15-2004$

\title{
Structures and stability of medium silicon clusters. II. Ab initio molecular orbital calculations of $\mathrm{Si}_{12}-\mathrm{Si}_{20}$
}

X.-L. Zhu

University of Nebraska-Lincoln

Xiao Cheng Zeng

University of Nebraska-Lincoln, xzeng1@unl.edu

Y.A. Lei

University of Nebraska-Lincoln

B. Pan

University of Science and Technology of China, Hefei, 230000, China

Follow this and additional works at: https://digitalcommons.unl.edu/chemzeng

Part of the Chemistry Commons

Zhu, X.-L.; Zeng, Xiao Cheng; Lei, Y.A.; and Pan, B., "Structures and stability of medium silicon clusters. II. $\mathrm{Ab}$ initio molecular orbital calculations of $\mathrm{Si}_{12}-\mathrm{Si}_{20}$ " (2004). Xiao Cheng Zeng Publications. 27.

https://digitalcommons.unl.edu/chemzeng/27

This Article is brought to you for free and open access by the Published Research - Department of Chemistry at DigitalCommons@University of Nebraska - Lincoln. It has been accepted for inclusion in Xiao Cheng Zeng Publications by an authorized administrator of DigitalCommons@University of Nebraska - Lincoln. 


\title{
Structures and stability of medium silicon clusters. II. Ab initio molecular orbital calculations of $\mathrm{Si}_{12}-\mathbf{S i}_{20}$
}

\author{
X. L. Zhu, X. C. Zeng, ${ }^{\text {a) }}$ and Y. A. Lei \\ Department of Chemistry, University of Nebraska-Lincoln, Lincoln, Nebraska 68588 \\ B. Pan \\ Department of Physics, University of Science and Technology of China, Hefei, 230000, China
}

(Received 5 December 2003; accepted 6 February 2004)

\begin{abstract}
$A b$ initio all-electron molecular-orbital calculations are carried out to study the structures and relative stability of low-energy silicon clusters $\left(\mathrm{Si}_{n}, n=12-20\right)$. Selected geometric isomers include those predicted by Ho et al. [Nature (London) 392, 582 (1998)] based on an unbiased search with tight-binding/genetic algorithm, as well as those found by Rata et al. [Phys. Rev. Lett. 85, 546 (2000)] based on density-functional tight-binding/single-parent evolution algorithm. These geometric isomers are optimized at the Møller-Plesset (MP2) MP2/6-31G $(d)$ level. The single-point energy at the coupled-cluster single and double substitutions (including triple excitations) $[\mathrm{CCSD}(\mathrm{T})] \operatorname{CCSD}(\mathrm{T}) / 6-31 \mathrm{G}(d)$ level for several low-lying isomers are further computed. Harmonic vibrational frequency analysis at the MP2/6-31G(d) level of theory is also undertaken to assure that the optimized geometries are stable. For $\mathrm{Si}_{12}-\mathrm{Si}_{17}$ and $\mathrm{Si}_{19}$ the isomer with the lowest-energy at the $\operatorname{CCSD}(\mathrm{T}) / 6-31 \mathrm{G}(d)$ level is the same as that predicted by Ho et al., whereas for $\mathrm{Si}_{18}$ and $\mathrm{Si}_{20}$, the same as predicted by Rata et al. However, for $\mathrm{Si}_{14}$ and $\mathrm{Si}_{15}$, the vibrational frequency analysis indicates that the isomer with the lowest CCSD $(\mathrm{T}) / 6-31 \mathrm{G}(d)$ single-point energy gives rise to imaginary frequencies. Small structural perturbation onto the $\mathrm{Si}_{14}$ and $\mathrm{Si}_{15}$ isomers can remove the imaginary frequencies and results in new isomers with slightly lower MP2/6-31G $(d)$ energy; however the new isomers have a higher single-point energy at the $\operatorname{CCSD}(\mathrm{T}) / 6-31 \mathrm{G}(d)$ level. For most $\mathrm{Si}_{n}(n=12-18,20)$ the low-lying isomers are prolate in shape, whereas for $\mathrm{Si}_{19}$ a spherical-like isomer is slightly lower in energy at the CCSD(T)/6-31G $(d)$ level than low-lying prolate isomers. (C) 2004 American Institute of Physics. [DOI: 10.1063/1.1690755]
\end{abstract}

\section{INTRODUCTION}

Over the past 15 years, medium-sized silicon clusters $\mathrm{Si}_{n}(n>10)$ have attracted much attention both experimentally ${ }^{1-8}$ and theoretically. ${ }^{9-41}$ Considerable effort has been devoted to determine the ground-state geometric structures, namely, the global minima as a function of the cluster size $n$. For $n \leqslant 7$, the global minima are firmly established by both $a b$ initio calculations and Raman/infrared spectroscopy measurements, whereas for $n \leqslant 12$ the global minima based on $a b$ initio calculations ${ }^{11,16,29,30}$ are well accepted. For $13 \leqslant n \leqslant 24$, unbiased search for the global minima has been undertaken based on either the genetic algorithm coupled with semi-empirical tight-binding (TB) technique, ${ }^{23}$ or the single-parent evolution algorithm coupled with density-functional (DF) TB and density-functional theory (DFT) methods. ${ }^{27,38}$ For $\mathrm{Si}_{25}$, several candidates for the lowest-energy isomers have been proposed based on $a b$ initio quantum Monte $\mathrm{Carlo}^{26}$ or high-level molecular orbital calculations. ${ }^{41}$ For $n>25$, the global minima based on either semi-empirical or $a b$ initio methods are largely unexplored. A recent $a b$ initio investigation of the relative stability of 17 isomers of $\mathrm{Si}_{36}$ has been reported. ${ }^{40}$ It is known that as the size of cluster increases, finding the global-minimum struc-

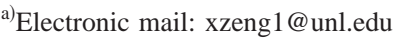

ture becomes increasingly difficult because of the much increased complexity of the potential surface as well as the rapid increase of the number of low-energy isomers.

For silicon cation clusters $\mathrm{Si}_{n}^{+}$, ion mobility experiments have revealed a structural transition from prolate to more spherical-like geometries, which occurs in between $24<n$ $<30{ }^{2,3}$ For neutral silicon clusters, however, photoionization experiments ${ }^{5}$ have shown that the prolate-to-sphericallike structural transition may occur in between $20 \leqslant n \leqslant 22$. On the theoretical side, early ab initio calculations suggested that the critical size for the structural transition is bounded by $24<n<28 .{ }^{13}$ The more recent unbiased semi-empirical TB calculation in conjunction with the DFT optimization for the final structures ${ }^{23}$ indicated that a spherical-like $\mathrm{Si}_{19}$ isomer (containing an endohedral atom) becomes slightly more stable than the low-lying prolate $\mathrm{Si}_{19}$ isomers.

In our previous paper (Paper I), ${ }^{30}$ we reported allelectron molecular-orbital calculations of geometric structures, energies, vibrational frequencies, as well as ionization potentials for small low-lying silicon clusters $\left(\mathrm{Si}_{n}, n\right.$ $=7-11)$. In this paper, we extend the all-electron molecularorbital approach to medium-sized silicon clusters $\left(\mathrm{Si}_{n}, n\right.$ $=12-20$ ). Selected low-energy isomers are those predicted by Ho et $_{\text {al. }}{ }^{23}$ based on an unbiased search with TB/genetic algorithm, as well those found by Rata et al. ${ }^{27}$ based on the unbiased search with DFTB/single-parent evolution algo- 
rithm. Energies of these medium-sized clusters have been calculated only at the DF level of theory. It is thus useful and important to confirm their stability via vibrational frequency analysis and to further examine their relative stability by using high-level all-electron molecular-orbital methods.

\section{COMPUTATIONAL DETAILS}

As in Paper $\mathrm{I},{ }^{30}$ we used molecular-orbital methods at the MP2/6-31G(d)//CCSD(T)/6-31G(d) level of theory, compiled in the GAUSSIAN 98 software package. ${ }^{42}$ The MP2/6-31G $(d)$ level of theory is selected for geometry relaxation to approximately account for the correlation effect of all electrons to the geometric structures. Honea et al. ${ }^{43}$ have demonstrated that the MP2/6-31G $(d)$ level of theory is required in order to correctly predict the tetragonal bipyramidal ground-state structure of the magic-number cluster $\mathrm{Si}_{6}$. The Hartree-Fock (HF) level of theory on the other hand gives rise to the ground-state structure of $\mathrm{Si}_{6}$ to be either capped trigonal bipyramid or bicapped tetrahedron, which disagrees with the measured ground-state structure. ${ }^{43}$ In previous benchmark calculations by us at the MP2/6-31G $(d)$ level $^{30}$ we found that the calculated $\mathrm{Si}-\mathrm{Si}$ bond lengths typically deviate from the measurements by only $0.5 \%$. To identify the most stable isomer among nearly degenerated isomers, the $\operatorname{CCSD}(\mathrm{T}) / 6-31 \mathrm{G}(d)$ single-point energy calculation was performed. Moreover, for the isomer with the lowest $\operatorname{CCSD}(\mathrm{T}) / 6-31 \mathrm{G}(d)$ energy its stability was further examined by calculating its vibrational frequencies at the MP2/6-31G $(d)$ level of theory. As mentioned earlier,

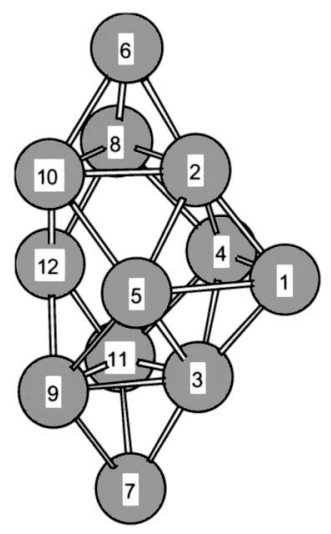

$12 \mathrm{a}\left(\mathrm{C}_{2 \mathrm{v}}\right)$

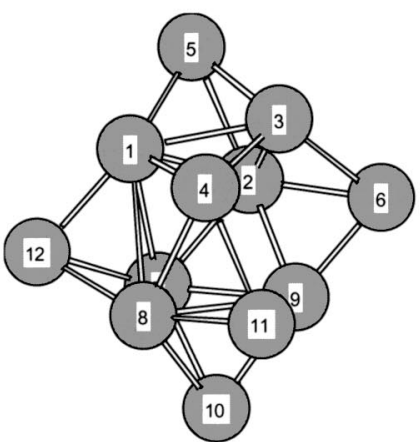

$12 \mathrm{e}\left(\mathrm{C}_{1}\right)$

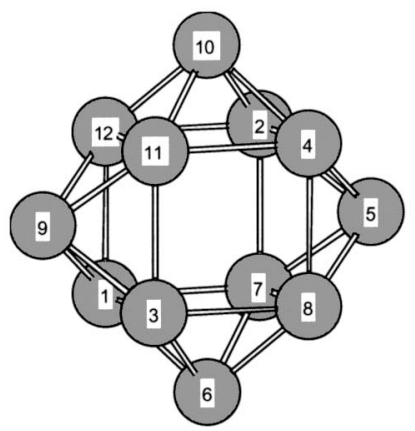

$12 \mathbf{i}\left(\left(\mathbf{D}_{4 h}\right)\right.$

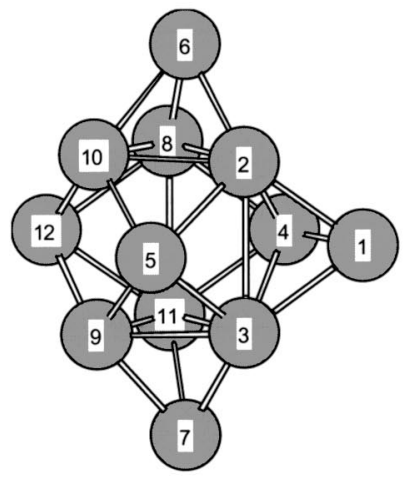

$12 \mathrm{~b}\left(\mathrm{C}_{\mathrm{s}}\right)$

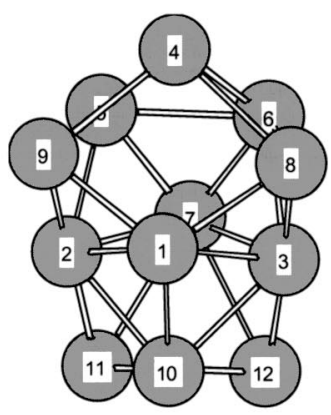

$12 f\left(C_{s}\right)$

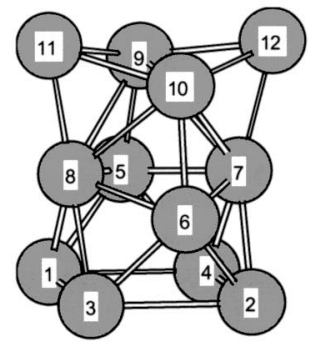

$12 \mathrm{j}\left(\mathrm{C}_{2 \mathrm{v}}\right)$

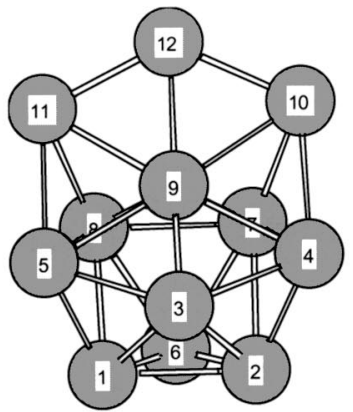

$12 \mathrm{c}\left(\mathrm{C}_{\mathrm{s}}\right)$

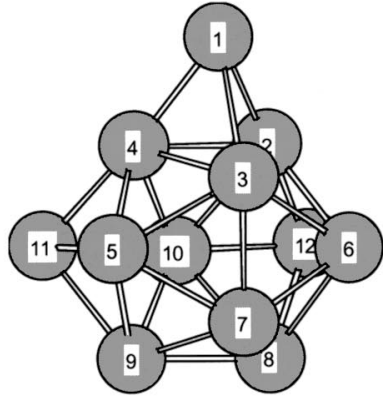

$12 g\left(C_{s}\right)$

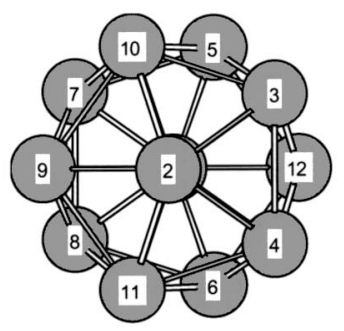

$12 \mathrm{k}\left(\mathrm{C}_{5 \mathrm{v}}\right)$

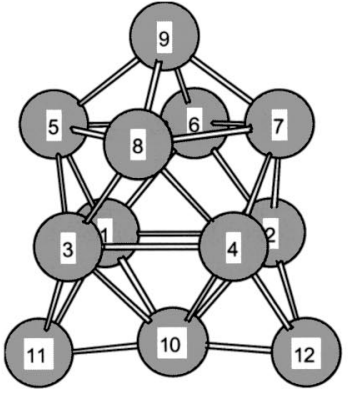

$12 \mathrm{~d}\left(\mathrm{C}_{2 \mathrm{v}}\right)$

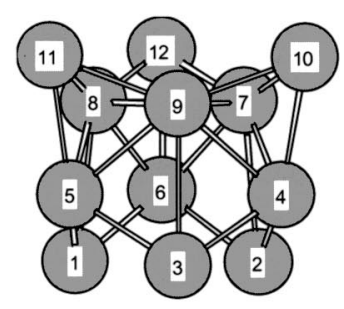

$12 \mathrm{~h}\left(\mathrm{C}_{3 \mathrm{v}}\right)$

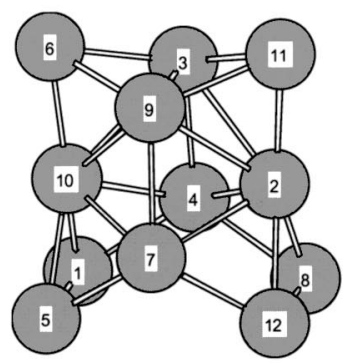

$121\left(C_{2 v}\right)$

FIG. 1. Geometries of the low-energy structures of $\mathrm{Si}_{12}-\mathrm{Si}_{20}$ optimized at the MP2/6-31G(d) level. 


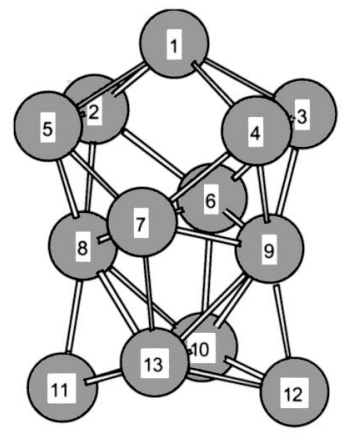

$13 a\left(C_{2 v}\right)$

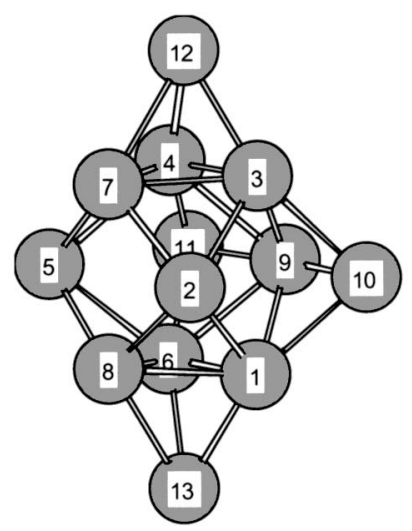

$13 c\left(C_{2 v}\right)$

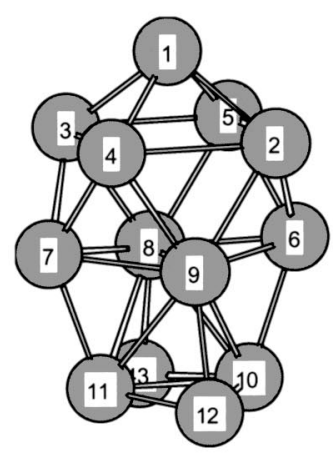

$13 e\left(C_{2 v}\right)$

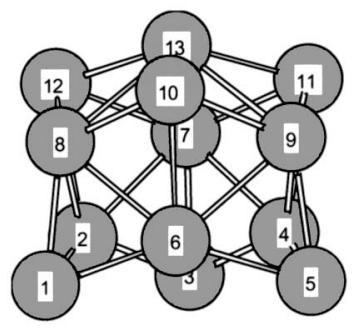

$13 b\left(C_{3 v}\right)$

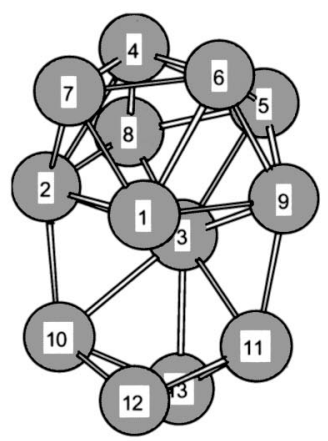

$\operatorname{13d}\left(C_{1}\right)$

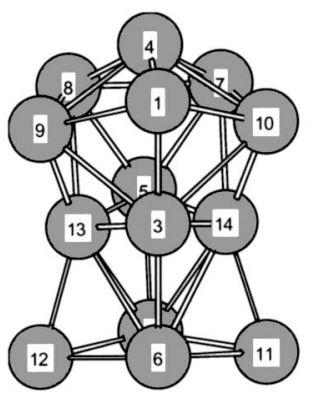

$14 \mathrm{a}\left(\mathrm{C}_{\mathrm{s}}\right)$
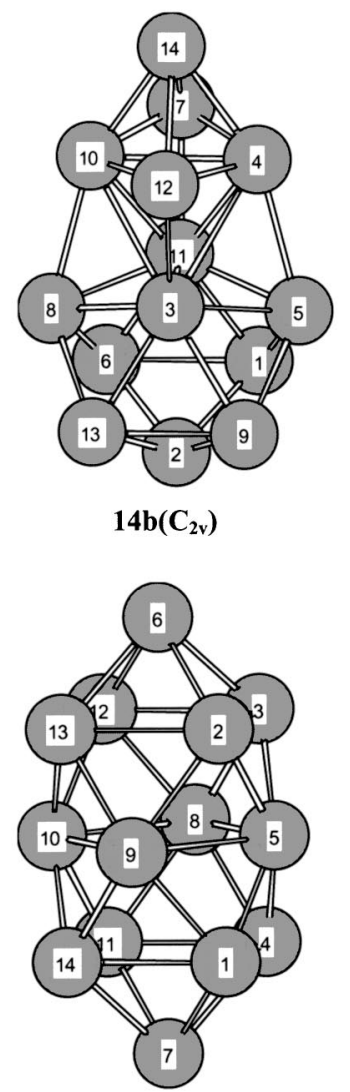

$\operatorname{14d}\left(\mathrm{D}_{2 \mathrm{~h}}\right)$
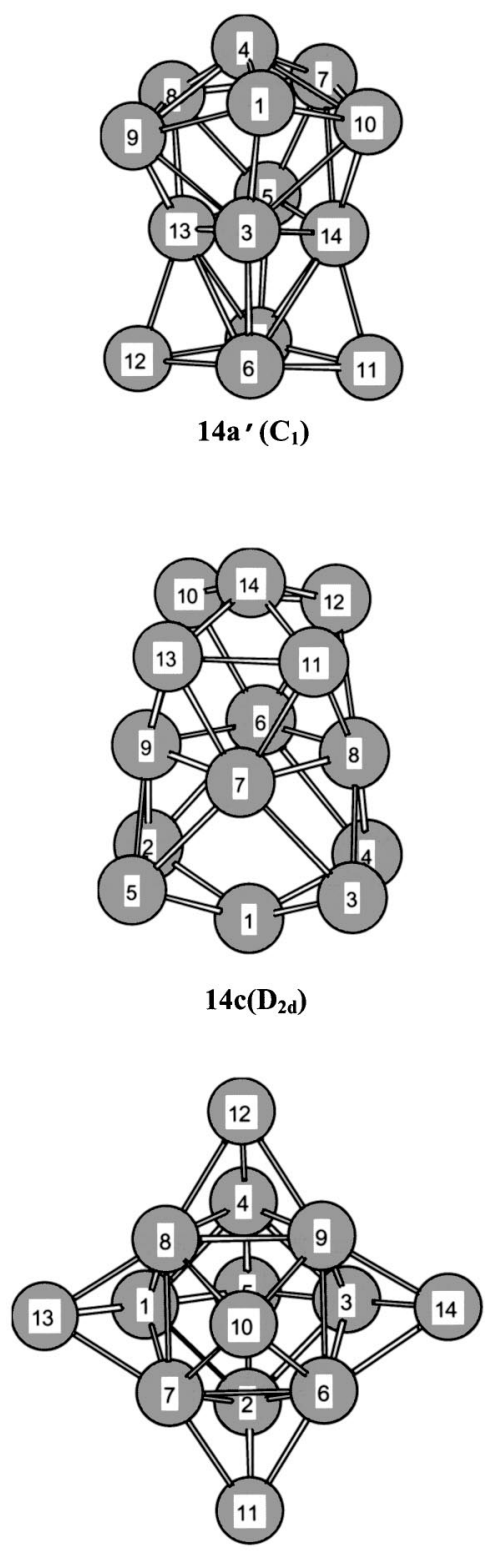

$14 \mathrm{e}\left(\mathrm{C}_{4 \mathrm{v}}\right)$

FIG. 1. (Continued.)

structures of the low-lying isomers of $\mathrm{Si}_{12}-\mathrm{Si}_{20}$ have been reported in the literature, ${ }^{23,27}$ and some of them are possibly true global minima.

\section{RESULTS AND DISCUSSIONS}

The optimized geometric structures of the selected lowenergy isomers $\mathrm{Si}_{n}(n=12-20)$ are plotted in Fig. 1, where all $\mathrm{Si}-\mathrm{Si}$ distances less than $2.95 \AA$ are ascribed as $\mathrm{Si}-\mathrm{Si}$ "bonds." The single-point energies at various levels of theory are summarized in Table I. Isomers that have the lowest energy at each level of theory are listed in Table II. For the isomers with the lowest $\operatorname{CCSD}(\mathrm{T}) / 6-31 \mathrm{G}(d)$ energy their vibrational frequencies were calculated at the MP2/6-31G $(d)$ level of theory. The vibrational frequency analysis confirmed that all the isomers with the lowest $\operatorname{CCSD}(\mathrm{T}) / 6-31 \mathrm{G}(d)$ energy are stable except for $\mathrm{Si}_{14}(14 \mathrm{a})$ and $\mathrm{Si}_{15}(15 \mathrm{a})$. For $14 \mathrm{a}$, one imaginary frequency was found while for $15 \mathrm{a}$ two imaginary frequencies were found, even after a tight structural optimization at the MP2/6-31G(d) level. To remove the imaginary frequencies, the geometry of $14 \mathrm{a}$ and $15 \mathrm{a}$ was slightly perturbed. After geometric relaxation with the perturbed structure, new isomers $14 \mathrm{a}^{\prime}$ and $15 \mathrm{a}^{\prime}$ were obtained, both show no imaginary frequencies. They all have slightly lower MP2/6-31G $(d)$ energy but show slightly higher $\operatorname{CCSD}(\mathrm{T}) / 6-31 \mathrm{G}(d)$ energy than the original isomers (14a and 15a), respectively. The calculated vibrational frequencies for these stable isomers are listed in Table III.

\section{A. Optimized geometric structure 1. $n=12$}

For $\mathrm{Si}_{12}$ cluster, the isomer with the lowest $\operatorname{CCSD}(\mathrm{T}) / 6-31 \mathrm{G}(d)$ energy, 12a, is a hexacapped trigonal 


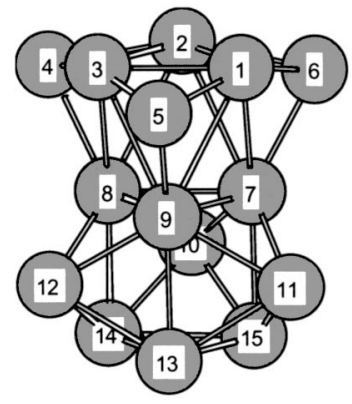

$15 \mathrm{a}\left(\mathrm{C}_{3 \mathrm{v}}\right)$

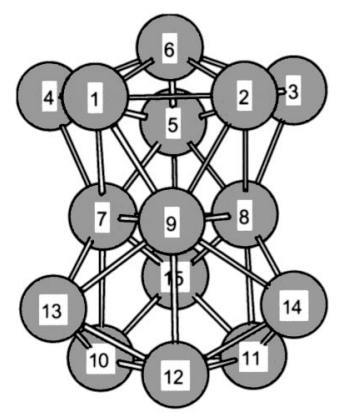

$15 c\left(C_{s}\right)$

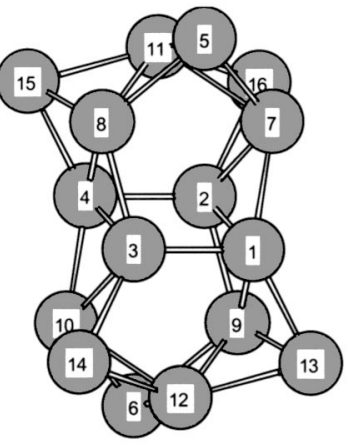

$16 a\left(C_{2 h}\right)$
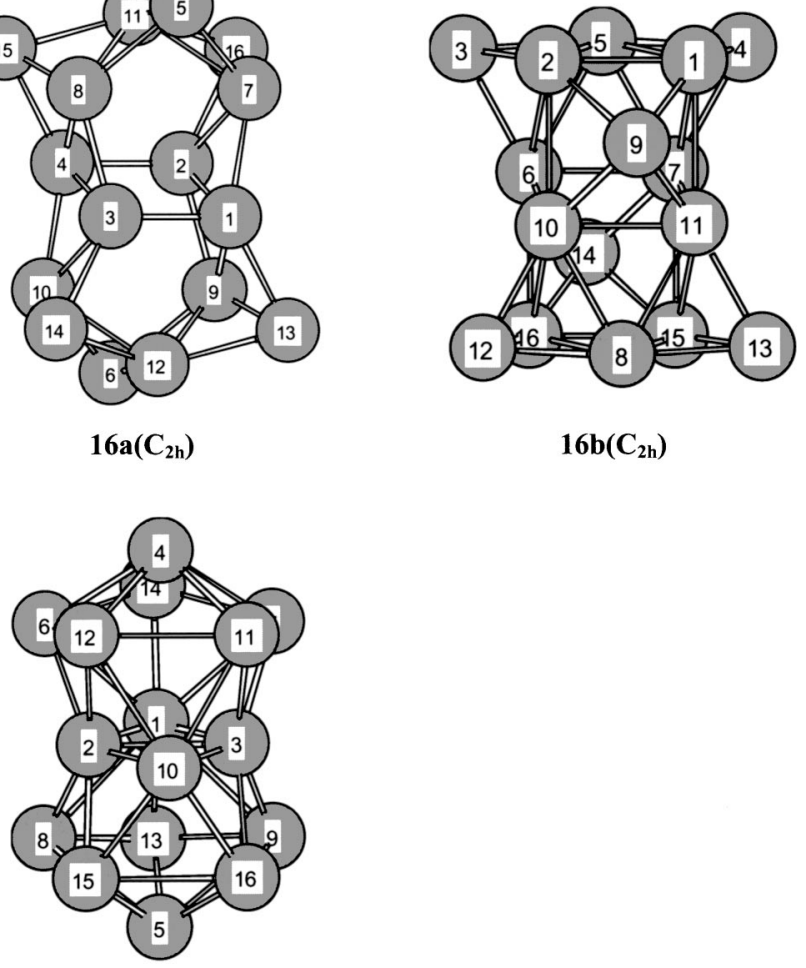

$16 b\left(C_{2 h}\right)$

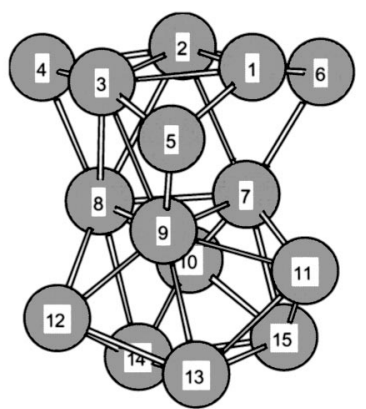

$15 b\left(C_{s}\right)$

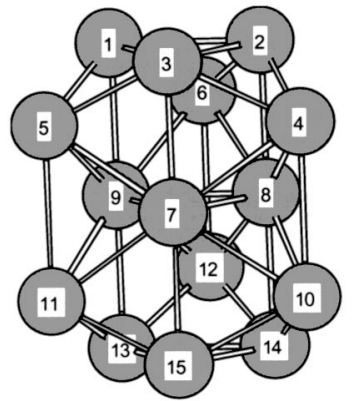

$15 d\left(D_{3 h}\right)$

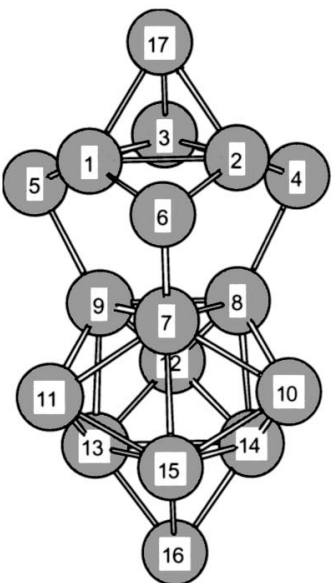

$17 \mathrm{a}\left(\mathrm{C}_{3 \mathrm{v}}\right)$

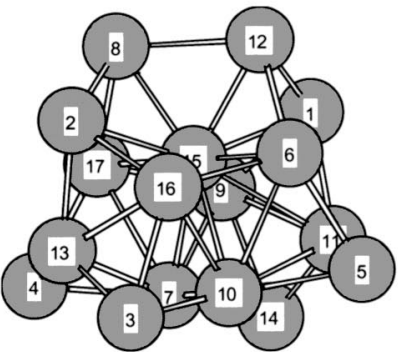

$17 \mathrm{e}\left(\mathrm{C}_{2}\right)$

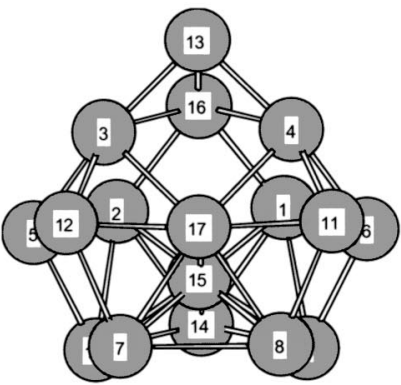

$17 b\left(C_{s}\right)$

FIG. 1. (Continued.)

$\mathrm{Si}_{10}$-Ref. 30 (tetracapped trigonal prism). Bahel and Ramakrishna ${ }^{16}$ have performed an extensive search for the ground-state isomer of $\mathrm{Si}_{12}$ within the framework of TBMD and DF theory. Their isomer 2 with $C_{s}$ symmetry is similar to $12 \mathrm{a}$. Isomer $12 \mathrm{~b}$ is very similar to $12 \mathrm{a}$ in structure. In fact, both isomers $12 \mathrm{a}$ and $12 \mathrm{~b}$ exhibit the 1-3-4-3-1 layered structure, with different arrangements of atoms in the third layer. Bahel and Ramakrishna have examined 15 isomers of $\mathrm{Si}_{12}$ and shown that the pentagonal and tetragonal prismatic families are higher in energy than the trigonal prismatic family. Similar conclusion can be reached here after examining several new low-energy isomers (Fig. 1).

\section{2. $n=13$}

Much more theoretical studies ${ }^{15,17,19,23,32,34-36,38,39}$ have been devoted to the $\mathrm{Si}_{13}$ cluster because of the possibility of finding a high-symmetry $\left(I_{h}\right)$ core-based icosahedral structure. ${ }^{32}$ It was later shown that the high-symmetry icosahedral cluster is unstable due to the Jahn-Teller distortion. ${ }^{35}$ Using a quantum Monte Carlo method, ${ }^{17}$ Grossman and Mitas investigated several isomers of $\mathrm{Si}_{13}$ and found that the $C_{3 v}$ trigonal antiprism isomer $13 \mathrm{~b}$ is more stable than the core-based icosahedral $\operatorname{Si}_{13}\left(I_{h}\right)$. Here we also confirmed that the core-based icosahedral $\mathrm{Si}_{13}$ is unstable. The most stable structure, $13 \mathrm{a}$, is identical to the reported lowest-energy structure based on DF-TB calculation. ${ }^{19}$ Isomer 13a can be described as a distorted tricapped trigonal prism with an ad-

prism with $C_{2 v}$ symmetry as previously predicted via TB calculations ${ }^{16,23}$ as well as ab initio Car-Parrinello molecular dynamics simulated annealing. ${ }^{29} 12 \mathrm{a}$ can be constructed by adding two capping atoms to the global-minimum of 

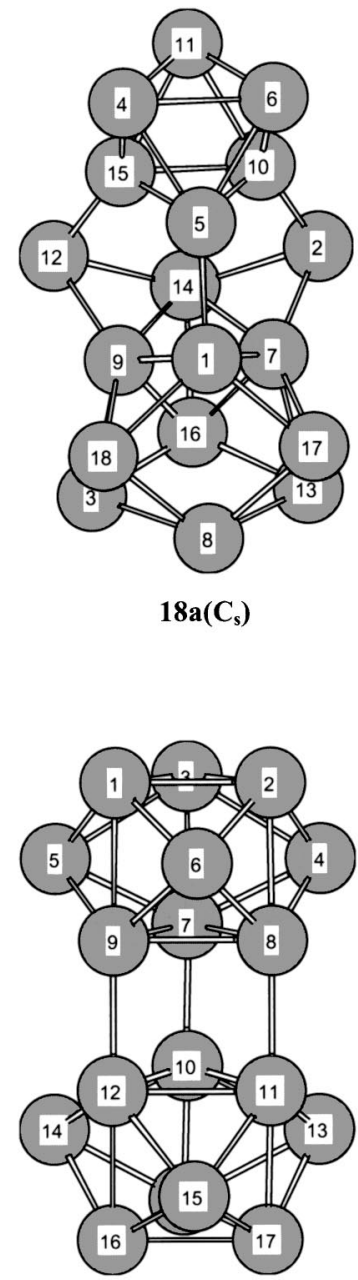

$18 \mathrm{c}\left(\mathrm{C}_{2 \mathrm{v}}\right)$
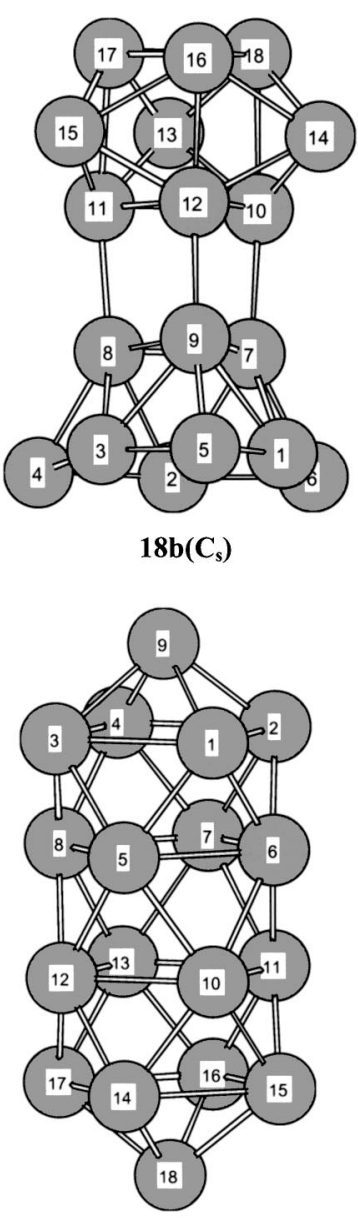

$18 d\left(D_{4 d}\right)$

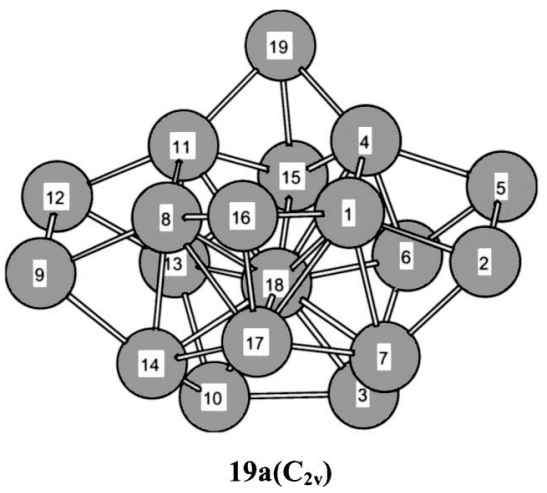

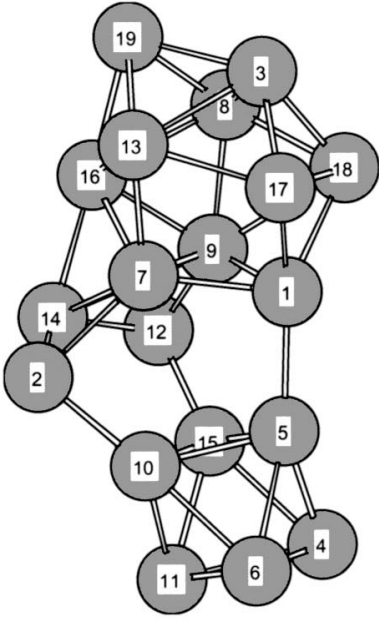

$19 b\left(C_{1}\right)$

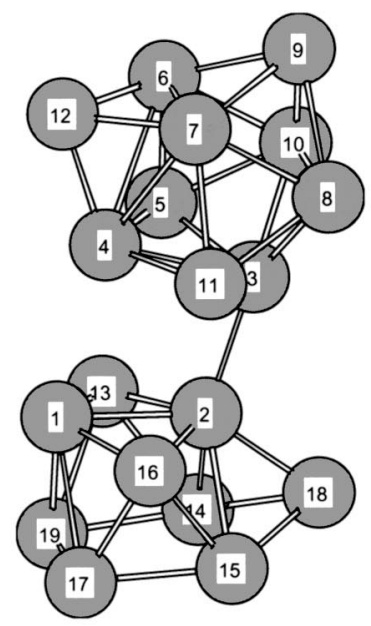

$19 \mathrm{c}\left(\mathrm{C}_{\mathrm{s}}\right)$

FIG. 1. (Continued.)

ditional rhombus capped on one edge of the prism. Ho et al. ${ }^{23,29}$ have found that the lowest-energy isomer of $\mathrm{Si}_{13}$ has $C_{S}$ symmetry, which can be viewed as a slightly distorted $13 \mathrm{a}\left(\mathrm{C}_{2 v}\right)$. The $\mathrm{C}_{3 v}$ capped trigonal antiprism, ${ }^{17} 13 \mathrm{~b}$, is slightly higher in energy than $13 \mathrm{a}[0.16 \mathrm{eV}$ at the $\operatorname{CCSD}(\mathrm{T}) / 6-31 \mathrm{G}(d)$ level]. Isomers based on capped trigonal prism motif (13c and 13d) are also very close in energy to 13a. Like 13a, isomer 13e has a stacking sequence of three rhombi with a capped atom but 13e is higher in energy than 13a.

\section{3. $n=14$}

For $\mathrm{Si}_{14}$ cluster, a number of low-lying isomers have been reported in the literature. ${ }^{15,19,23,38,39}$ General consensus was that the isomer $14 \mathrm{a}\left(C_{s}\right)$ found by Sieck et al. ${ }^{19}$ is possibly the global minimum. 14a has two stacked rhombi with distortion and one fivefold ring capped with an atom. As mentioned earlier, it is found that at the MP2/6-31G $(d)$ level of theory, the vibrational frequency analysis indicates isomer 14a has one imaginary frequency. A structural perturbation followed by geometry relaxation gives isomer $14 \mathrm{a}^{\prime}\left(C_{1}\right)$ which is very close in structure to $14 \mathrm{a}$. $14 \mathrm{a}^{\prime}$ also exhibits a stacking sequence of two distorted rhombi, one fivefold ring, and an atom on top. Isomers $14 \mathrm{~b}, 14 \mathrm{c}$, and $14 \mathrm{~d}$ all exhibit a stacking sequence of three (distorted) rhomibi with one atom on top and one at the bottom. Their energy is much higher than $14 \mathrm{a}$ and $14 \mathrm{a}^{\prime}$. Isomer $14 \mathrm{e}$ has a capped trigonal-prism unit and is also much higher in energy than $14 \mathrm{a}$ and $14 \mathrm{a}^{\prime}$.

\section{4. $n=15$}

For $\mathrm{Si}_{15}$ cluster, the low-lying clusters $(15 \mathrm{a}-15 \mathrm{~d})$ all contain the capped trigonal-prism unit, as revealed from the unbiased TB search. ${ }^{23}$ The isomer having the lowest energy at the $\operatorname{CCSD}(\mathrm{T}) / 6-31 \mathrm{G}(d)$ level is $15 \mathrm{a}\left(C_{3 v}\right)$ whose geometry is a tricapped trigonal prism fused with a tricapped trigonal antiprism. It has been reported that the calculated mobility of isomer $15 \mathrm{a}$ agreed with the mobility measurements. ${ }^{23}$ However, vibrational frequency analysis at the MP2/6-31G $(d)$ level shows that 15 a has two imaginary frequencies. Thus, isomer $15 \mathrm{a}\left(C_{3 v}\right)$ may not be a stable structure but a transition-state structure at the MP2/6-31G $(d)$ level of theory. As mentioned earlier a structural perturbation to $15 \mathrm{a}$ followed by geometry relaxation gives rise to isomer $15 \mathrm{a}^{\prime}$ with $C_{s}$ symmetry. $15 \mathrm{a}^{\prime}$ shows no imaginary frequency and its MP2 energy is $0.025 \mathrm{eV}$ lower that that of $15 \mathrm{a}$ but its $\operatorname{CCSD}(\mathrm{T})$ energy becomes $0.19 \mathrm{eV}$ higher than that of $15 \mathrm{a}$. 


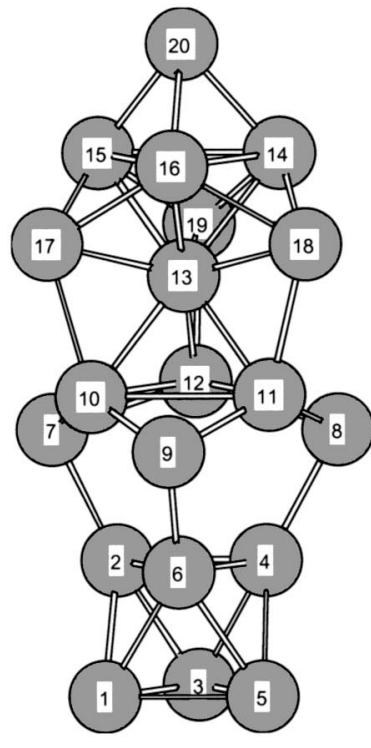

$20 a\left(C_{3 v}\right)$

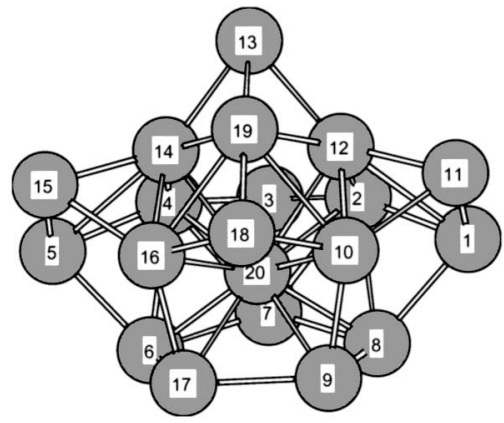

$20 \mathrm{c}\left(\mathrm{C}_{\mathrm{s}}\right)$

FIG. 1. (Continued)

\section{5. $n=16$ and 17}

For $\mathrm{Si}_{16}$ cluster, it is found that 16 a with $C_{2 h}$ symmetry gives the lowest energy at the $\operatorname{CCSD}(\mathrm{T}) / 6-31 \mathrm{G}(\mathrm{d})$ level, similar to the prediction by Ho et al. ${ }^{23} 16 \mathrm{a}$ can be described as two fused pentagonal prisms. Its structure is unique in the sense that it is neither based on the tricapped trigonal-prism motif (as 16b) nor based on a stacking sequence of fourfold and fivefold rings with capping atoms (as 16c). On the other hand, for $\mathrm{Si}_{17}$ cluster, 17a with $C_{3 v}$ symmetry is possibly the lowest-energy structure as predicted by Ho et al. ${ }^{23}$ and it does contain a tricapped-trigonal-prism (TTP) unit and a hexagonal-chair unit. The six-atom hexagonal-chair unit can be viewed as a fragment in bulk diamond silicon. ${ }^{9}$ It is interesting to note that the more spherical-like $\mathrm{Si}_{17}$ isomer, $17 \mathrm{c}$, is very competitive in stability compared to the prolateshaped isomer 17a.

\section{6. $n=18$}

For $\mathrm{Si}_{18}$ cluster, four low-lying isomers considered are shown in Fig. 1. The elongated 18a has the lowest-energy at the $\operatorname{CCSD}(\mathrm{T}) / 6-31 \mathrm{G}(\mathrm{d})$ level. 18a has the structure similar to the ground-state structure of $\mathrm{Si}_{18}^{+}$, predicted-by Rata et al. ${ }^{27}$ It contains a magic-number-cluster $\mathrm{Si}_{6}$ unit and a hexagonal- chair unit. Another previously predicted lowest-energy isomer of $\mathrm{Si}_{18}$ with $C_{3 v}$ symmetry gives imaginary frequencies at the MP2/6-31G(d) level. Again, a slight structural perturbation to this $C_{3 v}$ isomer followed by geometry relaxation gives isomer $18 \mathrm{~b}$ with $C_{s}$ symmetry. Both $18 \mathrm{~b}$ and $18 \mathrm{c}$ contain tricapped-trigonal-prism unit and both are very competitive in stability compared to $18 \mathrm{a}$. $18 \mathrm{~d}$ is a new isomer with high symmetry but relatively high energy. It is composed of two capped tetragonal antiprisms.

\section{7. $n=19$}

For $\mathrm{Si}_{19}$ cluster, a spherical-like isomer $19 \mathrm{a}$ was found by Ho et al. ${ }^{23}$ The isomer $19 \mathrm{~b}$ which contains a tetra-cappedtrigonal-prism unit and a magic-number-cluster $\mathrm{Si}_{6}$ unit is very competitive in stability compared with $19 \mathrm{a}$. $19 \mathrm{~b}$ was found based on a novel single-parent evolution algorithm coupled with DFTB/DFT methods. Isomer $19 \mathrm{c}^{23}$ is composed of a TTP unit and a $\mathrm{Si}_{10}$ (bicapped tetrahedral antiprism) unit. Its energy is slightly higher than both 19a and $19 b$.

\section{8. $n=20$}

Finally, for $\mathrm{Si}_{20}$ cluster, the lowest-energy isomer appears to be $20 \mathrm{a}$, as predicted by Rata et al. ${ }^{27}$ from the unbiased DFTB search. 20a is composed of three units: a magicnumber cluster $\mathrm{Si}_{6}$ unit, a hexagonal-chair unit in the middle, and a low-energy isomer of $\mathrm{Si}_{8}$ unit (see isomer $8 \mathrm{f}$ in Ref. 30 ). $20 \mathrm{~b}$ is another low-lying isomer which is composed of two $\mathrm{Si}_{10}$ (bicapped tetrahedral antiprism) units. 20b was first predicted by Mitas et al. ${ }^{26}$ on the basis of quantum Monte Carlo calculation. Isomer $20 \mathrm{c}^{23}$ exhibits compact sphericallike structure and its energy is slightly higher than both prolate-shaped isomer 20a and $20 \mathrm{~b}$.

\section{B. Relative stability, binding energy, and ionization potential}

As shown in Tables I and II, unequivocal determination of the lowest-energy cluster can be very tricky sometimes if only low-level $a b$ initio calculation of the single-point energies is considered. Taking $\mathrm{Si}_{13}$ as an example, one can see from Tables I and II that the HF energies indicate $13 \mathrm{c}$ has the lowest energy, but MP2 energies indicated $13 \mathrm{~d}$ has the lowest energy, and MP3 energies show $13 \mathrm{c}$ has the lowest energy. However, MP4, CCSD, and CCSD(T) energies can lead to consistent prediction, that is, 13a has the lowest energy. This example demonstrates the sensitivity of low-lying structures to the electron correlation effect. It is known that MP2 and MP3 levels of theory can only partially account for the correlation effects whereas $\operatorname{CCSD}(\mathrm{T})$ calculation provides much more reliable prediction to the relative stability among low-lying isomers. It is interesting to note from Table II that there exists some systematic correlation between HF, MP3, CCSD, and DFT energies, ${ }^{23,27}$ particularly for larger clusters. Namely, the isomer (optimized at the MP2 level) with the lowest HF energy is likely to have lowest MP3, CCSD, and DFT energies.

One can also see from Table II that the spherical-like compact isomers (for $n>13$ ), such as $14 \mathrm{e}, 17 \mathrm{~b}, 17 \mathrm{c}$, and $20 \mathrm{c}$, are generally higher in energy than the prolate-shaped 
TABLE I. Energies of low-energy isomers of $\mathrm{Si}_{12}-\mathrm{Si}_{20}$ (optimized at the MP2/6-31G* level).

\begin{tabular}{|c|c|c|c|c|c|c|c|}
\hline \multirow[b]{2}{*}{ Cluster } & \multicolumn{6}{|c|}{ Energy (hartrees) } & \multirow[b]{2}{*}{$\operatorname{CCSD}(\mathrm{T}) / 6-31 \mathrm{G}^{*}$} \\
\hline & Isomer (PG) & $\mathrm{HF} / 6-31 \mathrm{G}^{*}$ & MP2/6-31G* & MP3/6-31G* & MP4(SDQ)/6-316* & CCSD/6-31G* & \\
\hline \multirow[t]{12}{*}{$\mathrm{Si}_{12}$} & $12 \mathrm{a}\left(C_{2 v}\right)$ & -3466.75512 & -3467.97520 & -3467.87303 & -3467.96718 & -3467.92573 & -3468.03985 \\
\hline & $12 \mathrm{~b}\left(C_{s}\right)$ & -3466.72241 & -3467.96359 & -3467.84017 & -3467.94730 & -3467.90060 & -3468.02069 \\
\hline & $12 \mathrm{c}\left(C_{s}\right)$ & -3466.68583 & -3467.94708 & & & & \\
\hline & $12 \mathrm{~d}\left(C_{2 v}\right)$ & -3466.72986 & -3467.94023 & & & & \\
\hline & $12 \mathrm{e}\left(C_{1}\right)$ & -3466.74850 & -3467.93946 & & & & \\
\hline & $12 \mathrm{f}\left(C_{s}\right)$ & -3466.68104 & -3467.92139 & & & & \\
\hline & $12 \mathrm{~g}\left(C_{s}\right)$ & -3466.71823 & -3467.91483 & & & & \\
\hline & $12 \mathrm{~h}\left(C_{3 v}\right)$ & -3466.67983 & -3467.91127 & & & & \\
\hline & $12 \mathrm{i}\left(D_{4 h}\right)$ & -3466.56063 & -3467.90996 & & & & \\
\hline & $12 \mathrm{j}\left(C_{2 v}\right)$ & -3466.69196 & -3467.90872 & & & & \\
\hline & $12 \mathrm{k}\left(C_{5 v}\right)$ & -3466.63861 & -3467.90709 & & & & \\
\hline & $121\left(C_{2 v}\right)$ & -3466.68552 & -3467.89061 & & & & \\
\hline \multirow[t]{5}{*}{$\mathrm{Si}_{13}$} & $13 \mathrm{a}\left(C_{2 v}\right)$ & -3755.63003 & -3756.96913 & -3756.84336 & -3756.96160 & -3756.90811 & -3757.03672 \\
\hline & $13 \mathrm{~b}\left(C_{3 v}\right)$ & -3755.61327 & -3756.97766 & -3756.82469 & -3756.95555 & -3756.89645 & -3757.03083 \\
\hline & $13 \mathrm{c}\left(C_{2 v}\right)$ & -3755.64918 & -3756.93009 & -3756.85441 & -3756.94309 & -3756.90497 & -3757.02206 \\
\hline & $13 \mathrm{~d}\left(C_{1}\right)$ & -3755.56551 & -3756.98007 & -3756.78147 & -3756.95525 & -3756.87312 & -3757.01430 \\
\hline & $13 \mathrm{e}\left(C_{2 v}\right)$ & -3755.61319 & -3756.94700 & & & & \\
\hline \multirow[t]{6}{*}{$\mathrm{Si}_{14}$} & $14 \mathrm{a}\left(C_{s}\right)$ & -4044.55049 & -4046.00155 & -4045.85063 & -4045.99609 & -4045.92942 & -4046.06746 \\
\hline & $14 \mathrm{a}^{\prime}\left(C_{1}\right)$ & -4044.54918 & -4046.00186 & -4045.84948 & -4045.99511 & -4045.92843 & -4046.06682 \\
\hline & $14 \mathrm{~b}\left(C_{2 v}\right)$ & -4044.46678 & -4045.97563 & & & & \\
\hline & $14 \mathrm{c}\left(D_{2 d}\right)$ & -4044.36501 & -4045.94439 & & & & \\
\hline & $14 \mathrm{~d}\left(D_{2 h}\right)$ & -4044.42521 & -4045.91731 & & & & \\
\hline & $14 \mathrm{e}\left(C_{4 v}\right)$ & -4044.50395 & -4045.88855 & & & & \\
\hline \multirow[t]{5}{*}{$\mathrm{Si}_{15}$} & $15 \mathrm{a}\left(C_{3 v}\right)$ & -4333.46412 & -4335.01653 & -4334.84831 & -4335.01694 & -4334.93923 & -4335.08644 \\
\hline & $15 \mathrm{a}^{\prime}\left(C_{s}\right)$ & -4333.44466 & -4335.01745 & -4334.83050 & -4335.01383 & -4334.92846 & -4335.07936 \\
\hline & $15 \mathrm{~b}\left(C_{s}\right)$ & -4333.40289 & -4335.02713 & -4334.79494 & -4335.01622 & -4334.90869 & -4335.06669 \\
\hline & $15 \mathrm{c}\left(C_{s}\right)$ & -4333.39623 & -4335.03009 & -4334.78567 & -4335.01792 & -4334.90474 & -4335.06465 \\
\hline & $15 \mathrm{~d}\left(D_{3 h}\right)$ & -4333.38959 & -4335.01206 & -4334.77387 & -4335.00314 & -4334.89148 & -4435.05033 \\
\hline \multirow[t]{3}{*}{$\mathrm{Si}_{16}$} & $16 \mathrm{a}\left(C_{2 h}\right)$ & -4622.40970 & -4623.98220 & -4623.89215 & -4623.98911 & -4623.94798 & -4624.09466 \\
\hline & $16 \mathrm{~b}\left(C_{2 h}\right)$ & -4622.32890 & -4624.00351 & -4623.80257 & -4623.99084 & -4623.90456 & -4624.06519 \\
\hline & $16 \mathrm{c}\left(C_{2 v}\right)$ & -4622.30809 & -4623.99182 & & & & \\
\hline \multirow[t]{3}{*}{$\mathrm{Si}_{17}$} & $17 \mathrm{a}\left(C_{3 v}\right)$ & -4911.26279 & -4913.02183 & -4912.84392 & -4913.01517 & -4912.93819 & -4913.10987 \\
\hline & $17 \mathrm{~b}\left(C_{s}\right)$ & -4911.08531 & -4913.01772 & & & & \\
\hline & $17 \mathrm{c}\left(C_{2}\right)$ & -4911.27245 & -4912.98860 & -4912.84280 & -4913.00312 & -4912.93085 & -4913.09769 \\
\hline \multirow[t]{4}{*}{$\mathrm{Si}_{18}$} & $18 \mathrm{a}\left(C_{s}\right)$ & -5200.19816 & -5202.01229 & -5201.87016 & -5202.02200 & -5201.95184 & -5202.12028 \\
\hline & $18 \mathrm{~b}\left(C_{s}\right)$ & -5200.17090 & -5202.01044 & -5201.84168 & -5202.01237 & -5201.93347 & -5202.10580 \\
\hline & $18 \mathrm{c}\left(C_{2 v}\right)$ & -5200.11961 & -5202.02297 & -5201.79854 & -5202.00700 & -5201.90960 & -5202.09200 \\
\hline & $18 \mathrm{~d}\left(D_{4 d}\right)$ & -5199.97608 & -5201.98373 & & & & \\
\hline \multirow[t]{3}{*}{$\mathrm{Si}_{19}$} & $19 \mathrm{a}\left(C_{2 v}\right)$ & -5489.09355 & -5491.03604 & -5490.84401 & -5491.04398 & -5490.95071 & -5491.13959 \\
\hline & $19 \mathrm{~b}\left(C_{1}\right)$ & -5489.08792 & -5491.01505 & -5490.85028 & -5491.02291 & -5490.94326 & -5491.12499 \\
\hline & $19 \mathrm{c}\left(C_{s}\right)$ & -5488.94244 & -5490.99257 & -5490.71492 & -5490.97524 & -5490.84903 & \\
\hline \multirow[t]{3}{*}{$\mathrm{Si}_{20}$} & $20 \mathrm{a}\left(C_{3 v}\right)$ & -5778.05691 & -5780.03342 & -5779.90677 & -5780.04979 & -5779.98642 & -5780.16709 \\
\hline & $20 \mathrm{~b}\left(C_{2 h}\right)$ & -5777.97542 & -5780.06229 & -5779.83927 & -5780.05763 & -5779.95316 & -5780.15034 \\
\hline & $20 \mathrm{c}\left(C_{s}\right)$ & -5777.96421 & -5780.06131 & -5779.81113 & -5780.05783 & -5779.93969 & \\
\hline
\end{tabular}

TABLE II. Lowest-energy isomers predicted based on various levels of theory.

\begin{tabular}{lccccccc}
\hline \hline Cluster & HF & MP2 & MP3 & MP4(SDQ) & CCSD & CCSD(T) & DFT $^{\mathrm{a}, \mathrm{b}}$ \\
\hline $\mathrm{Si}_{12}$ & $12 \mathrm{a}$ & $12 \mathrm{a}$ & $12 \mathrm{a}$ & $12 \mathrm{a}$ & $12 \mathrm{a}$ & $12 \mathrm{a}$ & $12 \mathrm{a}$ \\
$\mathrm{Si}_{13}$ & $13 \mathrm{c}$ & $13 \mathrm{~d}$ & $13 \mathrm{c}$ & $13 \mathrm{a}$ & $13 \mathrm{a}$ & $13 \mathrm{a}$ & $13 \mathrm{a}$ \\
$\mathrm{Si}_{14}$ & $14 \mathrm{a}$ & $14 \mathrm{a}^{\prime}$ & $14 \mathrm{a}$ & $14 \mathrm{a}$ & $14 \mathrm{a}$ & $14 \mathrm{a}$ & $14 \mathrm{a}$ \\
$\mathrm{Si}_{15}$ & $15 \mathrm{a}$ & $15 \mathrm{c}$ & $15 \mathrm{a}$ & $15 \mathrm{c}$ & $15 \mathrm{a}$ & $15 \mathrm{a}$ & $15 \mathrm{a}$ \\
$\mathrm{Si}_{16}$ & $16 \mathrm{a}$ & $16 \mathrm{~b}$ & $16 \mathrm{a}$ & $16 \mathrm{~b}$ & $16 \mathrm{a}$ & $16 \mathrm{a}$ & $16 \mathrm{a}$ \\
$\mathrm{Si}_{17}$ & $17 \mathrm{c}$ & $17 \mathrm{a}$ & $17 \mathrm{a}$ & $17 \mathrm{a}$ & $17 \mathrm{a}$ & $17 \mathrm{a}$ & $17 \mathrm{a}$ \\
$\mathrm{Si}_{18}$ & $18 \mathrm{a}$ & $18 \mathrm{c}$ & $18 \mathrm{a}$ & $18 \mathrm{a}$ & $18 \mathrm{a}$ & $18 \mathrm{a}$ & $18 \mathrm{a}$ \\
$\mathrm{Si}_{19}$ & $19 \mathrm{a}$ & $19 \mathrm{a}$ & $19 \mathrm{~b}$ & $19 \mathrm{a}$ & $19 \mathrm{a}$ & $19 \mathrm{a}$ & $19 \mathrm{~b}$ \\
$\mathrm{Si}_{20}$ & $20 \mathrm{a}$ & $20 \mathrm{~b}$ & $20 \mathrm{a}$ & $20 \mathrm{c}$ & $20 \mathrm{a}$ & $20 \mathrm{a}$ & $20 \mathrm{a}$ \\
\hline \hline
\end{tabular}

${ }^{\mathrm{a}}$ Reference 23 .

${ }^{\mathrm{b}}$ Reference 27. 
TABLE III. Vibrational frequencies $\left(\mathrm{cm}^{-1}\right)$, IR intensities, and zero-point energies (ZPEs) of the stable isomers with the lowest $\operatorname{CCSD}(\mathrm{T}) / 6-31 \mathrm{G}^{*}$ energy.

\begin{tabular}{|c|c|c|c|c|c|}
\hline Cluster & Isomer (PG) & Vibrat & frequencies (IR & ensities) & $\mathrm{ZPE}(\mathrm{eV})$ \\
\hline $\mathrm{Si}_{12}$ & $12 \mathrm{a}\left(C_{2 v}\right)$ & $\begin{array}{r}98.3(0.29) \\
150.7(0.77) \\
229.1(0.70) \\
275.9(0.54) \\
310.1(1.35) \\
353.2(2.66) \\
363.5(0.39) \\
420.5(2.51) \\
555.0(3.76)\end{array}$ & $\begin{array}{l}136.9(0.01) \\
180.3(4.42) \\
254.5(0.18) \\
287.0(0.01) \\
310.6(1.30) \\
357.3(3.23) \\
364.5(0.35) \\
505.3(0.04)\end{array}$ & $\begin{array}{l}138.0(0.05) \\
220.1(0.02) \\
260.1(1.22) \\
291.4(5.39) \\
324.5(0.06) \\
362.2(0.02) \\
408.7(0.89) \\
550.0(2.98)\end{array}$ & 0.55 \\
\hline $\mathrm{Si}_{13}$ & $13 \mathrm{a}\left(C_{2 v}\right)$ & $\begin{array}{r}38.6(0.01) \\
154.4(1.46) \\
228.3(0.92) \\
279.2(0.60) \\
322.9(3.57) \\
355.7(5.70) \\
394.4(0.02) \\
501.2(0.01)\end{array}$ & $\begin{array}{l}128.0(0.69) \\
167.7(0.16) \\
230.7(0.05) \\
297.3(2.11) \\
326.0(3.33) \\
384.4(0.01) \\
430.8(5.86) \\
505.4(1.79)\end{array}$ & $\begin{array}{l}145.3(0.77) \\
212.6(3.72) \\
240.9(1.46) \\
310.4(7.38) \\
334.4(0.31) \\
392.5(0.93) \\
437.1(3.32)\end{array}$ & 0.59 \\
\hline $\mathrm{Si}_{14}$ & $14 \mathrm{a}^{\prime}\left(C_{1}\right)$ & $\begin{array}{c}46.2(0.11) \\
103.4(1.02) \\
164.4(0.51) \\
195.3(0.22) \\
225.3(0.24) \\
258.6(0.96) \\
283.6(0.67) \\
315.6(11.51) \\
349.3(3.07) \\
375.2(1.39) \\
428.5(0.99) \\
455.1(2.62)\end{array}$ & $\begin{array}{l}81.1(2.10) \\
146.3(0.57) \\
185.3(0.42) \\
207.5(0.87) \\
233.7(10.55) \\
271.3(0.10) \\
293.8(1.94) \\
328.1(2.06) \\
358.2(1.64) \\
394.9(0.32) \\
437.5(1.63) \\
470.3(1.57)\end{array}$ & $\begin{array}{c}86.2(0.85) \\
156.7(0.48) \\
187.8(1.47) \\
213.4(1.03) \\
246.1(2.04) \\
279.6(1.48) \\
300.6(0.07) \\
333.7(1.12) \\
359.7(10.67) \\
403.4(3.59) \\
443.1(2.42) \\
479.5(1.00)\end{array}$ & 0.63 \\
\hline $\mathrm{Si}_{15}$ & $15 \mathrm{a}^{\prime}\left(C_{s}\right)$ & $\begin{array}{l}44.9(4.13) \\
112.8(0.22) \\
170.2(3.72) \\
191.6(2.62) \\
204.7(4.25) \\
233.8(1.60) \\
272.4(2.25) \\
292.9(6.54) \\
331.8(20.16) \\
368.2(17.14) \\
400.9(6.66) \\
445.5(95.47) \\
480.7(0.80)\end{array}$ & $\begin{array}{c}50.8(0.12) \\
125.3(0.15) \\
179.6(0.09) \\
198.6(0.77) \\
210.6(0.34) \\
252.2(0.27) \\
283.0(0.29) \\
295.8(5.84) \\
335.2(3.88) \\
373.0(3.42) \\
410.8(37.00) \\
463.1(3.06) \\
525.1(2.35)\end{array}$ & $\begin{array}{r}81.5(0.14) \\
136.7(0.09) \\
187.3(2.38) \\
200.3(0.87) \\
230.2(2.77) \\
261.6(2.90) \\
286.2(0.38) \\
318.6(0.91) \\
342.4(9.92) \\
387.1(0.18) \\
430.5(2.23) \\
473.7(1.33) \\
537.8(6.19)\end{array}$ & 0.69 \\
\hline $\mathrm{Si}_{16}$ & $16 \mathrm{a}\left(C_{2 h}\right)$ & $\begin{array}{r}80.1(0.14) \\
152.5(0.76) \\
220.5(0.18) \\
270.1(1.08) \\
350.3(3.68) \\
417.3(1.03) \\
462.3(0.06)\end{array}$ & $\begin{array}{r}81.0(0.12) \\
162.6(1.77) \\
229.5(1.31) \\
277.0(1.10) \\
355.5(0.12) \\
418.2(6.19) \\
495.5(2.62)\end{array}$ & $\begin{array}{l}101.6(0.11) \\
167.9(1.15) \\
267.2(3.87) \\
283.3(6.66) \\
366.2(0.11) \\
433.8(1.32) \\
521.3(1.00)\end{array}$ & 0.77 \\
\hline $\mathrm{Si}_{17}$ & $17 \mathrm{a}\left(C_{3 v}\right)$ & $\begin{array}{c}64.3(0.04) \\
150.3(0.03) \\
208.0(0.37) \\
227.9(37.24) \\
269.2(1.38) \\
330.4(1.14) \\
372.3(0.52)\end{array}$ & $\begin{array}{r}93.7(0.45) \\
153.6(0.10) \\
209.8(0.37) \\
246.0(2.86) \\
282.8(0.43) \\
354.3(6.26) \\
375.3(7.66)\end{array}$ & $\begin{array}{l}105.0(204.35) \\
175.3(55.71) \\
218.8(1.78) \\
264.6(1.05) \\
284.8(6.04) \\
362.5(1.33) \\
406.6(0.27)\end{array}$ & 0.78 \\
\hline
\end{tabular}


TABLE III. (Continued.)

\begin{tabular}{|c|c|c|c|c|c|}
\hline \multirow[t]{3}{*}{ Cluster } & \multirow[t]{3}{*}{ Isomer (PG) } & \multicolumn{3}{|c|}{ Vibrational frequencies (IR intensities) } & \multirow[t]{2}{*}{$\mathrm{ZPE}(\mathrm{eV}$} \\
\hline & & $421.1(5.67)$ & 451.2(19.99) & $451.7(0.91)$ & \\
\hline & & $488.5(5.46)$ & 499.4(1.34) & & \\
\hline \multirow[t]{17}{*}{$\mathrm{Si}_{18}$} & $18 \mathrm{a}\left(C_{s}\right)$ & & & & \\
\hline & & $35.7(0.06)$ & $87.9(0.06)$ & $92.5(0.18)$ & 0.85 \\
\hline & & $116.3(0.12)$ & $120.3(3.53)$ & $124.5(0.14)$ & \\
\hline & & $135.0(5.88)$ & $156.6(0.09)$ & $164.2(1.23)$ & \\
\hline & & $173.6(0.02)$ & $181.8(0.87)$ & $186.8(0.33)$ & \\
\hline & & $191.8(1.11)$ & $213.8(6.07)$ & $214.5(0.31)$ & \\
\hline & & $218.7(0.18)$ & $230.7(0.05)$ & $241.5(2.61)$ & \\
\hline & & $253.4(0.68)$ & $257.3(0.28)$ & $258.7(2.26)$ & \\
\hline & & $263.0(0.99)$ & $281.6(0.03)$ & $282.4(2.67)$ & \\
\hline & & $292.9(3.91)$ & $296.7(0.08)$ & $323.2(8.60)$ & \\
\hline & & $337.1(3.17)$ & $344.2(0.18)$ & $348.2(3.76)$ & \\
\hline & & $356.7(11.05)$ & $362.6(3.83)$ & $366.4(2.24)$ & \\
\hline & & $370.9(2.78)$ & $379.8(0.01)$ & $390.8(3.29)$ & \\
\hline & & $396.6(0.49)$ & $404.1(4.65)$ & $412.9(3.19)$ & \\
\hline & & $426.3(7.13)$ & $429.0(0.73)$ & $430.6(4.28)$ & \\
\hline & & $458.2(3.23)$ & $462.3(0.31)$ & 491.1(1.28) & \\
\hline & & $503.7(5.03)$ & $550.2(11.05)$ & & \\
\hline \multirow[t]{14}{*}{$\mathrm{Si}_{19}$} & $19 \mathrm{a}\left(C_{2 v}\right)$ & & & & \\
\hline & & $28.5(0.79)$ & $76.4(0.11)$ & $129.7(0.01)$ & 0.89 \\
\hline & & $143.8(0.23)$ & $156.4(0.04)$ & $162.9(0.97)$ & \\
\hline & & $169.6(0.13)$ & $187.0(0.18)$ & $192.1(2.41)$ & \\
\hline & & $212.5(0.05)$ & $212.8(0.01)$ & $219.8(0.13)$ & \\
\hline & & $233.2(5.02)$ & $233.9(0.46)$ & $244.5(1.26)$ & \\
\hline & & $245.9(0.05)$ & $253.6(1.60)$ & $281.6(3.72)$ & \\
\hline & & $289.0(4.33)$ & $294.7(2.77)$ & $298.3(0.01)$ & \\
\hline & & $313.5(1.94)$ & $316.8(0.20)$ & $345.7(0.02)$ & \\
\hline & & $362.4(0.26)$ & $381.1(0.72)$ & $385.5(0.27)$ & \\
\hline & & $390.1(1.23)$ & $418.0(3.55)$ & $418.3(4.21)$ & \\
\hline & & $420.5(3.50)$ & $430.7(5.62)$ & $445.5(5.65)$ & \\
\hline & & $445.8(12.03)$ & $467.1(0.46)$ & $475.2(3.89)$ & \\
\hline & & $483.9(1.88)$ & $505.2(0.47)$ & & \\
\hline \multirow[t]{10}{*}{$\mathrm{Si}_{20}$} & $20 \mathrm{a}\left(C_{3 v}\right)$ & & & & \\
\hline & & $60.5(0.11)$ & $121.5(0.08)$ & $138.4(1.05)$ & 0.96 \\
\hline & & $147.8(0.17)$ & $189.6(0.05)$ & $199.55(0.31)$ & \\
\hline & & $218.4(0.10)$ & $219.6(0.34)$ & $228.6(0.05)$ & \\
\hline & & $246.8(0.98)$ & $265.5(0.62)$ & $274.1(0.96)$ & \\
\hline & & 279.3(3.09) & $307.2(3.93)$ & $308.5(1.45)$ & \\
\hline & & $335.0(2.00)$ & $338.8(19.11)$ & $349.1(4.66)$ & \\
\hline & & $353.7(14.56)$ & $360.1(0.54)$ & $380.9(1.68)$ & \\
\hline & & $385.7(3.00)$ & $413.4(6.03)$ & $435.6(2.69)$ & \\
\hline & & $457.4(1.59)$ & $464.2(0.74)$ & $548.5(25.78)$ & \\
\hline
\end{tabular}

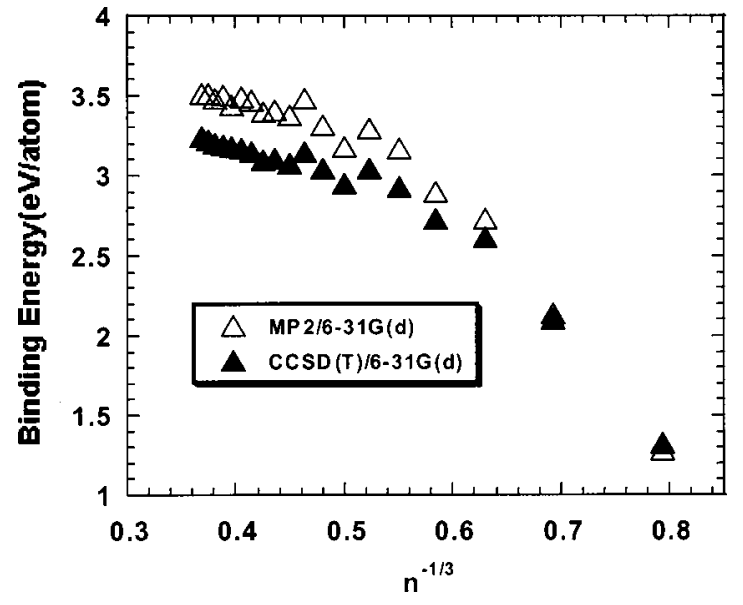

FIG. 2. Correlation of the binding energy per atom with $n^{-1 / 3}$ for the isomer of $\mathrm{Si}_{n}(n=12-20)$ with lowest energy at the $\operatorname{CCSD}(\mathrm{T}) / 6-31 \mathrm{G}(d)$ level.

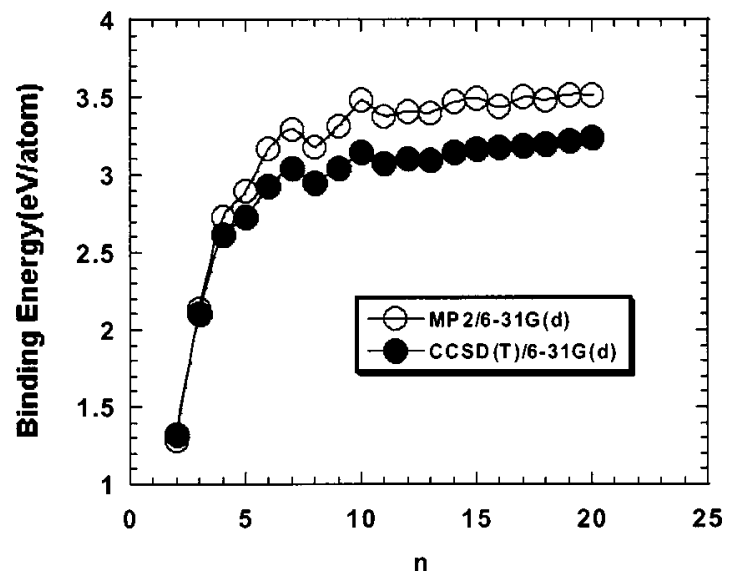

FIG. 3. Binding energy per atom of the isomer of $\operatorname{Si}_{n}(n=12-20)$ with the lowest energy at the $\operatorname{CCSD}(\mathrm{T}) / 6-31 \mathrm{G}(\mathrm{d})$ level vs cluster size $n$. 
TABLE IV. Vertical ionization potentials $\left(\mathrm{IP}_{v}\right)$ of the isomer of $\mathrm{Si}_{12}-\mathrm{Si}_{20}$ with the lowest $\operatorname{CCSD}(\mathrm{T}) / 6-31 \mathrm{G}^{*}$ energy.

\begin{tabular}{lcccc}
\hline \hline Cluster & Isomer & PG (state) & $\begin{array}{c}\mathrm{IP}_{v}(\text { Calc. }) \\
(\mathrm{eV})\end{array}$ & $\begin{array}{c}\mathrm{IP}(\text { Expt. })^{\mathrm{a}} \\
(\mathrm{eV})\end{array}$ \\
\hline $\mathrm{Si}_{12}$ & $12 \mathrm{a}$ & $C_{2 v}$ & 7.247 & $7.17-7.46$ \\
$\mathrm{Si}_{13}$ & $13 \mathrm{a}$ & $C_{2 v}$ & 7.523 & $7.17-7.46$ \\
$\mathrm{Si}_{14}$ & $14 \mathrm{a}^{\prime}$ & $C_{1}$ & 7.487 & $7.17-7.46$ \\
$\mathrm{Si}_{15}$ & $15 \mathrm{a}^{\prime}$ & $C_{s}$ & 7.224 & $7.17-7.46$ \\
$\mathrm{Si}_{16}$ & $16 \mathrm{a}$ & $C_{2 h}$ & 6.589 & $6.80-6.94$ \\
$\mathrm{Si}_{17}$ & $17 \mathrm{a}$ & $C_{3 v}$ & 7.182 & $7.46-7.53$ \\
$\mathrm{Si}_{18}$ & $18 \mathrm{a}$ & $C_{s}$ & 7.012 & $6.80-6.94$ \\
$\mathrm{Si}_{19}$ & $19 \mathrm{a}$ & $C_{2 v}$ & 6.463 & $6.80-6.94$ \\
$\mathrm{Si}_{20}$ & $20 \mathrm{a}$ & $C_{3 v}$ & 7.392 & $7.46-7.53$ \\
\hline \hline
\end{tabular}

${ }^{\mathrm{a}}$ Reference 5

isomers. One exception is the isomer $19 \mathrm{a}$ of $\mathrm{Si}_{19}$. In Fig. 2 we plot the binding energies of the lowest-energy isomers of $\mathrm{Si}_{12}-\mathrm{Si}_{20}$ as a function of $n^{-1 / 3}$ where $n$ is the cluster size. The deviation from the linear behavior for the bindingenergy versus $n^{-1 / 3}$ curve suggests the growth pattern of the low-lying medium-sized $\left(\mathrm{Si}_{12}-\mathrm{Si}_{20}\right)$ clusters deviates from the spherical growth pattern. ${ }^{44}$ Indeed, ion mobility measurements ${ }^{2,3}$ for $\mathrm{Si}_{n}^{+}$indicate that the appearance of spherical-like compact clusters only occurs for $n>23$. In Fig. 3 we plot the binding energy per atom as a function of the cluster size $n$. Two "bumps" can be seen at $n=6,7$, and 10 , corresponding to the magic-number clusters $\mathrm{Si}_{6}, \mathrm{Si}_{7}$, and $\mathrm{Si}_{10}$. For $n>10$, the binding energy per atom increases rather smoothly as a function of the cluster size $n$.

Finally, in Table IV, we present the calculated vertical ionization potential (IP) at the MP2/6-31G $(d)$ level for isomers with the lowest $\operatorname{CCSD}(\mathrm{T}) / 6-31 \mathrm{G}(d)$ energy. Measurement of the IPs has been reported by Fuke et al..$^{5}$ The measured IPs show an appreciable gap in between $n=20$ and 22, suggesting certain structural transition may occur for the neutral silicon clusters within this size range. The calculated vertical ionization potentials appear to correlate with the measured values reasonably well. For example, the vertical IP of the cluster 16a, 18a, and 19a is appreciably lower in value than the IP of their neighbor clusters, consistent with the measurement.

\section{CONCLUSIONS}

We have studied low-energy structures of $\mathrm{Si}_{12}-\mathrm{Si}_{20}$ at the MP2/6-31G $(d)$ level and their energies at the $\operatorname{CCSD}(\mathrm{T}) / 6-31 \mathrm{G}(d)$ level. The vibrational frequency analysis has been used to affirm the stability of the lowest-energy structures of $\mathrm{Si}_{12}-\mathrm{Si}_{20}$. The calculated vertical IP for the lowest-energy isomer of $\mathrm{Si}_{12}-\mathrm{Si}_{20}$ is mostly in good agreement with the measurement. The binding energy per atom as a function of $n^{-1 / 3}$ indicates that the low-lying $\mathrm{Si}_{12}-\mathrm{Si}_{20}$ clusters follow a nonspherical growth pattern.

We note that the lowest-energy structures of $\mathrm{Si}_{12}-\mathrm{Si}_{15}$ and $\mathrm{Si}_{17}$ all contain the TTP $\mathrm{Si}_{9}$ unit. Although the TTP $\mathrm{Si}_{9}$ unit is not a stand-alone local minimum, it appears to be a favorable building block ${ }^{23}$ for medium-sized clusters $\mathrm{Si}_{12}-\mathrm{Si}_{18}$. On the other hand, beginning with $\mathrm{Si}_{18}$ inclusion of the magic-number-cluster $\mathrm{Si}_{6}$ unit as well as the hexagonal-chair unit appears to be energically favorable over the inclusion of the TTP $\mathrm{Si}_{9}$ unit. The fact that a sphericallike $\mathrm{Si}_{19}$ isomer can be lower in energy at the $\operatorname{CCSD}(\mathrm{T}) / 6-31 \mathrm{G}(d)$ level of theory than low-lying prolateshaped isomers requires further investigation with larger basis sets. Another finding that may require further study is that some isomers (14a and 15a) with the lowest energy at $\operatorname{CCSD}(\mathrm{T}) / 6-31 \mathrm{G}(d)$ level can give imaginary vibrational frequencies, i.e., they could be transition-state structure. Slight structural distortion can remove the imaginary frequencies and lower the MP2 energy but can result in slightly higher $\operatorname{CCSD}(\mathrm{T})$ energy.

\section{ACKNOWLEDGMENTS}

We are very grateful for valuable discussions with Dr. Alex Shvartsburg, Dr. C.-Z. Wang, Professor K.-M. Ho, Professor Jin-Yan Zeng, and Soohaeng Yoo. This work is supported by the National Science Foundation and by the Research Computing Facility at the University of NebraskaLincoln.

${ }^{1}$ Y. Liu, Q.-L. Zhang, F. K. Tittel, R. F. Curl, and R. E. Smalley, J. Chem. Phys. 85, 7434 (1986); J. L. Elkind, J. M. Alford, F. D. Weiss, R. T. Laaksonene, and R. E. Smalley, ibid. 87, 2397 (1987); Q. L. Zhang, Y. Liu, R. F. Curl, F. K. Tittel, and R. E. Smalley, ibid. 88, 1670 (1988).

${ }^{2}$ M. F. Jarrold, Science 252, 1085 (1991); M. F. Jarrold and V. A. Constant, Phys. Rev. Lett. 67, 2994 (1991); M. F. Jarrold and J. E. Bower, J. Chem. Phys. 96, 9180 (1992).

${ }^{3}$ R. R. Hudgins, M. Imai, M. F. Jarrold, and P. Dugourd, J. Chem. Phys. 111, 7865 (1999); A. A. Shvartsburg, R. R. Hudgins, P. Dugourd, and M. F. Jarrold, Chem. Soc. Rev. 30, 36 (2001).

${ }^{4}$ K.-D. Rinnen and M. L. Mandich, Phys. Rev. Lett. 69, 1823 (1992).

${ }^{5}$ K. Fuke, K. Tsukamoto, F. Misaizu, and M. Sanekata, J. Chem. Phys. 99, 7807 (1993)

${ }^{6} \mathrm{~S}$. Li, R. J. Van Zee, W. Weltner, Jr., and K. Raghavachari, Chem. Phys. Lett. 243, 275 (1995).

${ }^{7}$ B. Marsen, M. Lonfat, P. Scheier, and K. Sattler, Phys. Rev. B 62, 6892 (2000).

${ }^{8}$ D. E. Bergeron and A. W. Castleman, Jr., J. Chem. Phys. 117, 3219 (2002).

${ }^{9}$ D. Tomanek and M. A. Schluter, Phys. Rev. Lett. 56, 1055 (1986); Phys. Rev. B 36, 1208 (1987).

${ }^{10}$ E. Kaxiras, Phys. Rev. Lett. 64, 551 (1990).

${ }^{11}$ C. M. Rohlfing and K. Raghavachari, Chem. Phys. Lett. 198, 521 (1990); ibid. 198, 521 (1992).

${ }^{12}$ B. C. Bolding and H. C. Andersen, Phys. Rev. B 41, 10568 (1990).

${ }^{13}$ E. Kaxiras and K. Jackson, Phys. Rev. Lett. 71, 727 (1993).

${ }^{14}$ P. Ordej, D. Lebedenko, and M. Menon, Phys. Rev. B 50, 5645 (1994).

${ }^{15}$ I. H. Lee, K. J. Chang, and Y. H. Lee, J. Phys.: Condens. Matter 6, 741 (1994).

${ }^{16}$ A. Bahel and M. V. Ramakrishna, Phys. Rev. B 51, 13849 (1995); M. V. Ramakrishna and A. Bahel, J. Chem. Phys. 104, 9833 (1996).

${ }^{17}$ J. C. Grossman and L. Mitas, Phys. Rev. Lett. 95, 1323 (1995).

${ }^{18}$ M. R. Pederson, K. Jackson, D. V. Porezag, Z. Hajnal, and Th. Frauenheim, Phys. Rev. B 54, 2863 (1996).

${ }^{19}$ A. Sieck, D. Porezag, Th. Frauenheim, M. R. Pederson, and K. Jackson, Phys. Rev. A 56, 4890 (1997).

${ }^{20}$ M. Menon and K. R. Subbaswamy, Phys. Rev. B 51, 17952 (1995).

${ }^{21}$ J. Song, S. E. Ulloa, and D. A. Drabold, Phys. Rev. B 53, 8042 (1996).

${ }^{22}$ I. Vasiliev, S. Ogut, and J. R. Chelikowsky, Phys. Rev. Lett. 78, 4805 (1997).

${ }^{23}$ K.-M. Ho, A. A. Shvartsburg, B. Pan, Z.-Y. Lu, C.-Z. Wang, J. G. Wacker, J. L. Fye, and M. F. Jarrold, Nature (London) 392, 582 (1998); B. Liu, Z.-Y. Lu, B. Pan, C.-Z. Wang, K.-M. Ho, A. A. Shvartsburg, and M. F. Jarrold, J. Chem. Phys. 109, 9401 (1998).

${ }^{24}$ A. A. Shvartsburg, M. F. Jarrold, B. Liu, Z.-Y. Lu, C.-Z. Wang, and K.-M. Ho, Phys. Rev. Lett. 81, 4616 (1998).

${ }^{25}$ U. Rothlisberger, W. Andreoni, and M. Parrinello, Phys. Rev. Lett. 72, 665 (1994). 
${ }^{26}$ L. Mitas, J. C. Grossman, I. Stich, and J. Tobik, Phys. Rev. Lett. 84, 1479 (2000).

${ }^{27}$ I. Rata, A. A. Shvartsburg, M. Horoi, Th. Frauenheim, K. W. M. Siu, and K. A. Jackson, Phys. Rev. Lett. 85, 546 (2000).

${ }^{28}$ B. X. Li and P. L. Cao, Phys. Rev. A 62, 023201 (2000).

${ }^{29}$ Z.-Y. Lu, C.-Z. Wang, and K.-M. Ho, Phys. Rev. B 61, 2329 (2001).

${ }^{30}$ X. Zhu and X. C. Zeng, J. Chem. Phys. 118, 3558 (2003).

${ }^{31}$ J. R. Chelikowsky, Phys. Rev. Lett. 60, 2669 (1988).

32 J. R. Chelikowsky and J. C. Philips, Phys. Rev. Lett. 63, 1653 (1989).

${ }^{33}$ K. Raghavachari, Phase Transitions 24-26, 61 (1990).

${ }^{34}$ U. Rothlisberger, W. Andreoni, and P. Giannozzi, J. Chem. Phys. 96, 1248 (1992).

${ }^{35}$ B.-L. Gu, Z.-Q. Li, and J.-L. Zhu, J. Phys.: Condens. Matter 5, 5255 (1993).

${ }^{36}$ B. C. Pan, C. Z. Wang, D. E. Turner, and K.-M. Ho, Chem. Phys. Lett. 292, 75 (1998).
${ }^{37}$ K. Jackson, M. Pederson, C.-Z. Wang, and K.-M. Ho, Phys. Rev. A 59, 3685 (1999).

${ }^{38}$ B.-X. Li, P.-L. Cao, and S.-C. Zhan, Phys. Lett. A 316, 252 (2003).

${ }^{39}$ S. N. Behera, B. K. Panda, S. Mukherjee, and P. Entel, Phase Transitions 75, 41 (2002)

${ }^{40}$ Q. Sun, Q. Wang, P. Jena, S. Waterman, and Y. Kawazoe, Phys. Rev. A 67, 063201 (2003).

${ }^{41}$ S. Yoo, X. C. Zeng, X. Zhu, and J. Bai, J. Am. Chem. Soc. 125, 13316 (2003).

${ }^{42}$ M. J. Frisch, G. W. Trucks, H. B. Schlegel et al., GAUSSIAN 98, Revision A.11, Gaussian, Inc., Pittsburgh, PA, 2002.

${ }^{43}$ E. C. Honea, A. Ogura, C. A. Murray, K. Raghavachari, W. O. Sprenger, M. F. Jarrold, and W. L. Brown, Nature (London) 366, 42 (1993).

${ }^{44}$ H. Haberland, Clusters of Atoms and Molecules: Theory, Experiment, and Clusters of Atoms (Springer, New York, 1994). 